AperTO - Archivio Istituzionale Open Access dell'Università di Torino

\title{
Effects of BaRuO3 addition on hydrogen desorption in $\mathrm{MgH2}$
}

\section{This is the author's manuscript}

Original Citation:

Availability:

This version is available http://hdl.handle.net/2318/93478

since 2016-08-20T17:26:42Z

Published version:

DOI:10.1016/j.jallcom.2011.12.008

Terms of use:

Open Access

Anyone can freely access the full text of works made available as "Open Access". Works made available under a Creative Commons license can be used according to the terms and conditions of said license. Use of all other works requires consent of the right holder (author or publisher) if not exempted from copyright protection by the applicable law. 


\section{(4) \\ UNIVERSITÀ DEGLI STUDI DI TORINO}

This Accepted Author Manuscript (AAM) is copyrighted and published by Elsevier. It is posted here by agreement between Elsevier and the University of Turin. Changes resulting from the publishing process - such as editing, corrections, structural formatting, and other quality control mechanisms may not be reflected in this version of the text. The definitive version of the text was subsequently published in JOURNAL OF ALLOYS AND COMPOUNDS 536 (2012) DOI 10.1016/j.jallcom.2011.12.008

You may download, copy and otherwise use the AAM for non-commercial purposes provided that your license is limited by the following restrictions:

(1) You may use this AAM for non-commercial purposes only under the terms of the CC-BY-NC-ND license.

(2) The integrity of the work and identification of the author, copyright owner, and publisher must be preserved in any copy.

(3) You must attribute this AAM in the following format: Creative Commons BY-NC-ND license (http://creativecommons.org/licenses/by-nc-nd/4.0/deed.en), 10.1016/j.jallcom.2011.12.008 


\title{
Effects of $\mathrm{BaRuO}_{3}$ addition on hydrogen desorption in $\mathrm{MgH}_{2}$
}

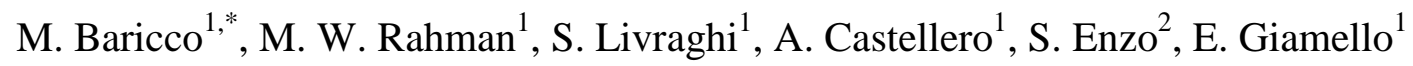

${ }^{1}$ Dipartimento di Chimica IFM and NIS, Università di Torino, Via P. Giuria 9, 10125, Torino, Italy

${ }^{2}$ Dipartimento di Chimica, Università di Sassari, Via Vienna, 2, 07100, Sassari, Italy

${ }^{\#}$ Corresponding author: marcello.baricco@unito.it

\section{Keywords}

Hydrogen storage; oxide bronze; $\mathrm{MgH} 2 ; \mathrm{BaRuO} 3$; kinetic analyis.

\begin{abstract}
Hydrogen storage in $\mathrm{MgH}_{2}$ is strongly limited by kinetic constraints, so that several additives have been considered in order to improve the rate of hydrogen desorption. The present work is devoted to investigate the effect of $\mathrm{BaRuO}_{3}$ addition on hydrogen absorption and desorption properties of $\mathrm{MgH}_{2} . \mathrm{BaRuO}_{3}$ was prepared by solid-state synthesis of $\mathrm{BaO}$ and $\mathrm{Ru}$ in oxidizing environment. The interaction of as-prepared $\mathrm{BaRuO}_{3}$ with hydrogen at room temperature was examined by thermal desorption and X-ray diffraction experiments, showing that $\mathrm{BaRuO}_{3}$ has the ability to uptake hydrogen in the bulk. The hydrogen interaction is discussed with respect to octahedral ruthenium local environment present in the oxide structure.
\end{abstract}

Addition of $1 \mathrm{~mol} \% \mathrm{BaRuO}_{3}$ to $\mathrm{MgH}_{2}$ was performed by ball milling. Hydrogen desorption properties were investigated by Sievert and DSC, connected with a $\mathrm{H}_{2}$ detector. The $\mathrm{H}_{2}$ 
desorbed from of the nano-structured materials is lower than the theoretical content in $\mathrm{MgH}_{2}$, due to the presence of a non-reactive $\mathrm{MgO}$ layer. A remarkable increase of the $\mathrm{H}_{2}$ desorption kinetics in nano-structured $\mathrm{MgH}_{2}$ was observed with respect to bare $\mathrm{MgH}_{2}$. The activation energy for hydrogen desorption from $\mathrm{MgH}_{2} / \mathrm{BaRuO}_{3}$ mixture was estimated by Arrhenius and Kissinger methods and a value around $130 \mathrm{kJmol}^{-1}$ and $90 \mathrm{kJmol}^{-1}$ was obtained, respectively.

\section{Introduction}

$\mathrm{MgH}_{2}$ is an excellent material due to its high hydrogen storage capacity. However, the equilibrium dehydrogenation temperature is high, around $570 \mathrm{~K}$ under 1 bar of $\mathrm{H}_{2}$ and the $\mathrm{ab} /$ desorption kinetics is undesirably slow [1-8]. A number of techniques has been applied to improve the ab/desorption kinetics of $\mathrm{MgH}_{2}$, for example, ball-milling [9-11] with different additives e.g., transition metals (TM) [12-14] and transition metal oxides (TMO) [15-20]. The addition of niobia $\left(\mathrm{Nb}_{2} \mathrm{O}_{5}\right)$, in particular, has demonstrated an increase of reactivity in $\mathrm{MgH}_{2}$ with respect to $\mathrm{H}_{2}$ uptake/release [9,21-25]. Recently, the interaction of hydrogen with $\mathrm{MgH}_{2}$ in presence of ternary Mg-Nb oxides has been studied [26], suggesting a prominent effect for the system $\mathrm{Mg}_{3} \mathrm{Nb}_{6} \mathrm{O}_{11}$. However, the exact role of additives on reaction mechanism still remained unclear. An empirical rule suggests that $\mathrm{TM}$ atoms ( $\mathrm{Nb}, \mathrm{Cr}, \mathrm{W}$ etc.) having multiple valence states in corresponding TMOs, show better reaction efficiency [7,21]. In addition, the interaction of $\mathrm{H}_{2}$ with TMOs has drawn attention in order to understand their specific role on $\mathrm{H}_{2} \mathrm{ab}$ /desorption reactions in $\mathrm{MgH}_{2}$ [27-32]. In particular, it has been suggested that the occurrence of a hydrogen absorption in the additive oxide phase may facilitate the overcome of the $\mathrm{MgO}$ layer formed at the surface of the $\mathrm{MgH}_{2}$ particles, leading to an improved reaction kinetics [25,26].

Chabanier et al. [33] performed electrochemical studies on $\mathrm{RuO}_{2}$ and $\mathrm{IrO}_{2}$ and suggested that these oxides show good electrocatalytic activity towards hydrogen evolution, leading to a 
$\mathrm{RuO}_{2} \mathrm{H}_{0.09}$ and $\mathrm{IrO}_{2} \mathrm{H}_{0.03}$ phases. Shelef et al. [34] reported that $\mathrm{BaRuO}_{3}$, after interaction with hydrogen $\left(\mathrm{H}_{2}\right.$ pressure $\left.40 \mathrm{kPa}\right)$ at room temperature (RT) for 6 days, absorbs $0.1 \mathrm{wt} \%$ hydrogen, corresponding to a $\mathrm{H}_{0.3} \mathrm{BaRuO}_{3}$ phase. These results suggest a specific investigation on the role of $\mathrm{BaRuO}_{3}$ addition on hydrogen desorption from $\mathrm{MgH}_{2}$.

In this paper, $\mathrm{BaRuO}_{3}$ has been prepared by solid-state reaction following the synthetic approach reported in the literature [35]. A preliminary study on the hydrogen interaction with the oxide phases has been performed, showing a significant hydrogen absorption at room temperature. In addition, $\mathrm{H}_{2}$ desorption kinetics in $\mathrm{MgH}_{2}$ promoted by ball-milling with 1 mol\% $\mathrm{BaRuO}_{3}$ has been investigated. The activation energy for hydrogen desorption has been estimated from isothermal and scanning measurements. It turns out significantly lower than that obtained for the bare $\mathrm{MgH}_{2}$ and comparable to those reported in the literature for different TMO additives [14,23].

\section{Experimental}

The starting materials used for solid-state synthesis of $\mathrm{BaRuO}_{3}$ were commercially barium oxide $(\mathrm{BaO})$ and ruthenium $(\mathrm{Ru})$ (Sigma-Aldrich, $99 \%$ pure). The compound was prepared by heating a stoichiometric mixture of reagents with a rate of $5 \mathrm{~K} / \mathrm{min}$ up to $1473 \mathrm{~K}$ and annealing for 24 hours in oxidizing environment. Reactive milling of pure $\mathrm{BaRuO}_{3}$ was performed in a commercial Spex model-8000 Mixer/Mill with a ball-to-powder mass ratio of 15:1 under a hydrogen pressure of $0.5 \mathrm{MPa}$ for $20 \mathrm{~h}$. Hydrogen absorption in as-prepared $\mathrm{BaRuO}_{3}$ was carried out at $\mathrm{RT}$ for $58 \mathrm{~h}$ with a hydrogen pressure of $6.5 \mathrm{MPa}$ inside of a Sievert-type apparatus. $1 \mathrm{~mol} \%$ of pure $\mathrm{BaRuO}_{3}$ was added to $5 \mathrm{~g}$ of commercial $\mathrm{MgH}_{2}$ (Alfa Aesar, Johnson Matthey Company, 98\% purity, balance $\mathrm{Mg}$ ) for ball-milling, carried out in a commercial Spex model-8000 Mixer/Mill for $12 \mathrm{~h}$ under a high purity Ar atmosphere. The milling run was carried out at $875 \mathrm{rpm}$ by employing a special hardened steel vial and two 
hardened steel milling balls with a ball-to-powder mass ratio of 7:1. Pure $\mathrm{MgH}_{2}$ was ball milled under the same conditions for comparison.

Structural features of solid-state materials have been analyzed by X-ray diffraction (XRD) at RT with an X'PERT PRO diffractometer (Panalytical) with $\mathrm{Cu} \mathrm{K} \alpha$ radiation. XRD patterns were collected in a step of 0.017 degree after accumulation of intensity data points in the range $10-100^{\circ}$ for $1 \mathrm{~h}$. Diffraction patterns were refined with Rietveld method using MAUD (Material Analysis Using Diffraction) program [36].

Hydrogen desorption properties were investigated by Thermal Programmed Desorption (TPD) coupled with a home-made heating apparatus to a quadruple Mass Spectrometer (MS, Pfeiffer Vacuum Prisma). Thermal desorption data were recorded during TPD measurements between $313 \mathrm{~K}$ and $1073 \mathrm{~K}$ with a heating rate of $7.5 \mathrm{~K} / \mathrm{min}$ in high vacuum $\left(10^{-6}\right.$ bar $)$ condition.

The samples were characterized by an AMC (Advanced Materials Corporation) instrument for hydrogen desorption at different programmed temperatures (573-653 K) in isothermal condition until reaching an equilibrium condition under a hydrogen pressure of $0.1 \mathrm{MPa}$. About $0.6 \mathrm{~g}$ sample were used for each measurement. Hydrogen desorption properties were also measured with a differential scanning calorimeter Perkin-Elmer DSC7. Measurements have been carried out with heating rate of 5, 10, 20 and $40 \mathrm{~K} / \mathrm{min}$. Two successive runs were performed and the data were subtracted from the signals of the second run defined as baseline.

\section{Results and discussion}

\section{Pure $\mathrm{BaRuO}_{3}$}

The XRD pattern of the product after the solid state synthesis of $\mathrm{BaO}+\mathrm{Ru}$ is shown in Figure 1 (pattern a). The use of a logarithmic scale is adopted for the analysis because intense and weak peaks may be equally important in order to correctly reconstruct the structure properties 
of materials. Indeed, the shift of the ordinate variable among the patterns is operated simply by multiplication of intensity data points by a constant factor. With this simple manipulation the signal-to-background trend is maintained, when adopting the same collection strategy in the instrument as well as the similar protocol of sample preparation in terms of density and chemistry. The Rietveld fit to the pattern $\left(\mathrm{R}_{\mathrm{wp}}=2.1 \%\right)$ confirms the rhombohedral structure of $\mathrm{BaRuO}_{3}$ (space group R-3m) with lattice parameters a $=5.752( \pm 0.001) \AA$ and $\mathrm{c}=21.623$ $( \pm 0.003) \AA$, that closely correspond to reference values given by the Inorganic Crystal Structure Database (ICSD) file 10253, within experimental uncertainty. Crystal size and microstrain of the ternary oxide are $>200 \mathrm{~nm}$ and $<3.9 \cdot 10^{-4}$, respectively, i. e., beyond the instrument resolution. The as-prepared $\mathrm{BaRuO}_{3}$ compound was investigated by hydrogen and water desorption (TPD-MS) and results are reported in Figure 2. The curve of as-prepared sample is a flat baseline, indicating that no desorption phenomena related to water and hydrogen release occurred.

The XRD pattern registered after reactive milling of $\mathrm{BaRuO}_{3}$ under $\mathrm{H}_{2}$ atmosphere is shown in Figure 1 (pattern b). The ternary oxide transformed during reactive milling due to the interaction of hydrogen, so that mono/tri-hydrated barium hydroxides $(25 \mathrm{wt} \% \pm 3 \%)$ and metallic $\mathrm{Ru}(28 \mathrm{wt} \% \pm 3 \%)$ were obtained, together with the parent oxide $(47 \mathrm{wt} \% \pm 5 \%)$. In addition, significant broadening of the diffraction peaks is observed due to formation of nanocrystalline solids $(10-90 \mathrm{~nm})$ during mechano-chemical treatment. The results suggests that reactive milling under $\mathrm{H}_{2}$ promotes chemical reactions with $\mathrm{BaRuO}_{3}$, leading to a reduction of $\mathrm{Ru}^{4+}$ to $\mathrm{Ru}^{0}$ and to the formation of $\mathrm{OH}^{-}$groups. The XRD pattern (not shown) remains rather similar after an annealing of the sample up to $950 \mathrm{~K}$, suggesting that the observed reactions are irreversible. So, a milder hydrogenation process has been explored.

Figure 1 (pattern c) shows the XRD pattern of $\mathrm{BaRuO}_{3}$ after interaction at $\mathrm{RT}$ with a $\mathrm{H}_{2}$ pressure of $6.5 \mathrm{MPa}$ for $58 \mathrm{~h}$. With respect to the as-prepared pattern, the lower signal-to- 
background ratio is due to peak distortion and broadening, on account for lattice parameter change of the rhombohedral structure. The XRD pattern was fit according to the Rietveld method $\left(\mathrm{R}_{\mathrm{wp}}=4.5 \%\right)$ and allowed the evidence of a consistent fraction $(33 \mathrm{wt} \% \pm 3 \%)$ of a new rhombohedral phase, with the same structure of $\mathrm{BaRuO}_{3}$, but with lattice parameters elongated in the c direction $(\mathrm{a}=5.755( \pm 0.001) \AA$ and $\mathrm{c}=21.819( \pm 0.003) \AA$,$) , together with$ a weak presence $(7 \mathrm{wt} \% \pm 1 \%)$ of a tetragonal phase, isostructural with $\mathrm{BaSrTiO}_{3}$ compound (ICSD, file 54150). These effects are related to the interaction of the original phase with hydrogen. In addition, the average crystallite size $(45 \mathrm{~nm} \pm 4)$ of the distorted phase obtained after hydrogenation at $6.4 \mathrm{MPa}$ is significantly reduced with respect to that of the as-prepared sample, together with an increase in the microstrain $\left(4.3 \cdot 10^{-3} \pm 2 \cdot 10^{-4}\right)$. Being the rest of the mixture constituted by the parent $\mathrm{BaRuO}_{3}$ rhombohedral phase, an incomplete hydrogenation reaction can be envisaged, in agreement with previous findings [34].

The TPD-MS spectra for hydrogen and water desorption from $\mathrm{BaRuO}_{3}$ after hydrogen absorption at 6.4 MPa are shown in Figure 2. Desorption peaks related to hydrogen and water are observed in similar positions, at temperatures starting from $400 \mathrm{~K}$ and $750 \mathrm{~K}$. Moreover, the hydrogen desorption peak intensity is about 30 times that related to water desorption, suggesting the occurrence of simple $\mathrm{H}_{2}$ insertion in the crystal structure, rather than a chemical interaction with oxide anions.

The XRD pattern after TPD-MS of $\mathrm{BaRuO}_{3}$ hydrogenated at RT under $6.4 \mathrm{MPa}$ is shown in Figure 1 (pattern d). The single rhombohedral $\mathrm{BaRuO}_{3}$ phase is assessed by the Rietveld refinement $\left(\mathrm{R}_{\mathrm{wp}}=3.36 \%\right)$, with lattice parameters $\mathrm{a}=5.750 \AA$ and $\mathrm{c}=21.611 \AA$, rather similar to those obtained for the as-prepared sample. The crystal size, above the resolution limit of $200 \mathrm{~nm}$, is remarkably increased after TPD-MS measurement, due to the microstructure coarsening. These results suggest a full recovering of the original structural properties after TPD-MS measurement, indicating a reversibility of the hydrogenation process in $\mathrm{BaRuO}_{3}$. 
Shelef et al. [34] reported that $\mathrm{BaRuO}_{3}$ absorbed $0.1 \mathrm{wt} \%$ hydrogen $\left(\mathrm{H}_{0.3} \mathrm{BaRuO}_{3}\right)$ at $\mathrm{RT}$ after interaction with hydrogen $\left(\mathrm{H}_{2}\right.$ pressure $\left.40 \mathrm{kPa}\right)$ for 6 days. From the reported results, it is worth noting that $\mathrm{BaRuO}_{3}$ is active to hydrogen absorption at RT even using much higher pressure $\left(\mathrm{H}_{2}\right.$ pressure $\left.6.4 \mathrm{MPa}\right)$. This behaviour has been already observed for other oxides, like $\mathrm{Mg}_{3} \mathrm{Nb}_{6} \mathrm{O}_{11}$ [37], $\mathrm{Nb}_{2} \mathrm{O}_{5}$ and $\mathrm{WO}_{3}$ [32].

The crystal structure of $\mathrm{BaRuO}_{3}$ has been derived by the bond valence method [38]. The crystal is based on a layered rhombohedral structure, which is considered to be the stable form of $\mathrm{BaRuO}_{3}$ at ambient pressure, confirmed by Rietveld refinement of as-prepared sample (Figure 1). The unary cell of $\mathrm{BaRuO}_{3}$ is formed by units of three face-sharing $\mathrm{RuO}_{6}$ octahedra, which are connected to one another by corner sharing. The crystalline Ru (IV) oxide $\left(\mathrm{RuO}_{2}\right)$ has the rutile-type structure and it is also composed of $\mathrm{RuO}_{6}$ octahedra. Recently, attention has been directed toward the use of $\mathrm{RuO}_{2}$ electrode as an activated cathode for $\mathrm{H}_{2}$ evolution. This oxide shows good electrocatalytic activity for $\mathrm{H}_{2}$ evolution and excellent resistance to deactivation due to deposition of metallic impurities [33]. The fact behind $\mathrm{H}_{2}$ interaction with $\mathrm{RuO}_{2}$ is that $\mathrm{H}_{2}$ can penetrate into the $\mathrm{RuO}_{2}$ structure in the absence of polarization. Moreover, the measured $\mathrm{H} / \mathrm{Ru}$ ratio suggests that surface hydroxylation occurs with no bulk modification. On the contrary, for $\mathrm{BaRuO}_{3}, \mathrm{H}_{2}$ absorption may occur also into the bulk of the material. In fact, the expansion of the unit cell has been noticed along the c-axis after $\mathrm{H}_{2}$ interaction (Figure 1), strongly suggesting that $\mathrm{H}_{2}$ is inserted in the a-b plane of the unary cell. The oxygen atoms of the shared faces in each unit are pulled together, thus providing a 'shielding effect' that reduces the Ru-Ru interactions, facilitating $\mathrm{H}_{2}$ incorporation and diffusion inside the structure.

Hydrogen absorption and desorption in $\mathrm{BaRuO}_{3}$ may be discussed according to reactions proposed for $\mathrm{H}_{2}$ interaction with $\mathrm{Nb}_{2} \mathrm{O}_{5}[39,40]$ :

$$
\mathrm{BaRuO}_{3}+x \mathrm{H}^{+}+x e^{-} \rightarrow \mathrm{H}_{x} \mathrm{BaRuO}_{3}
$$


$\mathrm{H}_{x} \mathrm{BaRuO}_{3} \rightarrow \mathrm{BaRu}^{4+} \mathrm{O}_{3}+x / 2 \mathrm{H}_{2}$

$\mathrm{H}_{x} \mathrm{BaRuO}_{3} \rightarrow \mathrm{BaRu}_{x}{ }^{3+} \mathrm{Ru}^{4+}{ }_{1-x} \mathrm{O}_{3-x / 2}+x / 2 \mathrm{H}_{2} \mathrm{O}$

In reaction 1, ionization of the incoming hydrogen occurs with release of electrons which can delocalize either into the conduction band of the solid or on a ruthenium ion, which changes its oxidation state. The residual $\mathrm{H}^{+}$is stabilized by oxygen ions of the lattice producing $\mathrm{OH}^{-}$ groups. Upon annealing, two possible reactive channels can be followed. In the first case (reaction 2), the process leads to hydrogen desorption and tends to restore the initial oxidation state of the transition metal. In the second case (reaction 3), the process leads to water desorption and the metal ion is partially reduced. So, $\mathrm{BaRuO}_{3}$ after contact with molecular hydrogen may be partially reduced by formation of hydroxyl groups and perhaps of hydride ions. Consequently, both hydrogen and water desorption can be explained on the basis of different bonding energy of $\mathrm{OH}^{-}$groups at various crystallographic sites.

In conclusion, $\mathrm{BaRuO}_{3}$ is not at all inert while interacting with hydrogen. This peculiar behavior, reminiscent of some properties of the bronze family and $\mathrm{Nb}_{2} \mathrm{O}_{5}$ [32], suggests a possible active chemical role played by $\mathrm{BaRuO}_{3}$ in the mixed $\mathrm{MgH}_{2} / \mathrm{BaRuO}_{3}$ system.

\section{$\mathrm{MgH}_{2}+\mathrm{BaRuO}_{3}$ mixture}

The XRD pattern of physically mixed $\mathrm{MgH}_{2}$ with $\mathrm{BaRuO}_{3}$ additive is shown in Figure 3 (bottom curve). In the parent $\mathrm{MgH}_{2}$ a small contamination (lower than 2 wt.\%) of hexagonal Mg was found. The XRD pattern in Figure 3 (upper curve) refers to the mixture after ball milling for $12 \mathrm{~h}$. The intensity of $\mathrm{MgH}_{2}$ diffraction profiles is affected by a large amount of peak broadening. The phase analysis evidences that tetragonal $\mathrm{MgH}_{2}$ is the main phase present (57 wt.\%) but 23 wt.\% of the sample is under the form of a $\gamma-\mathrm{MgH}_{2}$ orthorhombic phase, together with a non-negligible quantity of periclase $\mathrm{MgO}$ (15 wt.\%). The remaining 5 wt.\% of the mixture is attributed to $\mathrm{BaRuO}_{3}$, showing diffraction peaks with a lower degree of broadening, as expected from the brittleness of the oxide phase. The nominal amount of 
$\mathrm{BaRuO}_{3}$ present in $\mathrm{MgH}_{2}$ is $9.9 \mathrm{wt} \%$ ( $1 \mathrm{~mol} \%$ ). The reduced amount of pure $\mathrm{BaRuO}_{3}$ after ball milling might be related to an interaction of the additive with the $\mathrm{MgO}$ layer surrounding the $\mathrm{MgH}_{2}$ particles, suggesting a possible active role of the additive in the hydrogen sorption processes.

The results of the PCI experiment of $\mathrm{H}_{2}$ desorption from commercial $\mathrm{MgH}_{2}$, ball milled $\mathrm{MgH}_{2}$ and $\mathrm{MgH}_{2} / \mathrm{BaRuO}_{3}$ ball milled mixture at $593 \mathrm{~K}$ under $0.1 \mathrm{MPa}$ of hydrogen pressure are reported in Figure 4a. Because the total amount of hydrogen released from various samples is different, the results are reported as a transformed fraction as a function of time for better comparison. Commercial $\mathrm{MgH}_{2}$ shows very slow desorption rate, whereas ball milled $\mathrm{MgH}_{2}$ desorbs hydrogen much faster, as already reported in the literature [10]. $\mathrm{MgH}_{2} / \mathrm{BaRuO}_{3}$ ball milled mixture shows better desorption properties, due to the effect of ball milling and to the presence of the additive. Desorption curves for $\mathrm{MgH}_{2} / \mathrm{BaRuO}_{3}$ ball milled mixture from 653 to $573 \mathrm{~K}$ under $0.1 \mathrm{MPa} \mathrm{H}_{2}$ pressure are reported in Figure $4 \mathrm{~b}$, where the hydrogen release at various temperatures is reported as a function of time. The nominal hydrogen content in $\mathrm{MgH}_{2} / \mathrm{BaRuO}_{3}$ ball milled mixture is $6.9 \mathrm{wt} . \%$, respectively. The total amount of hydrogen desorbed from the samples is lower than the maximum nominal capacity, likely due to the presence of a non-reactive $\mathrm{MgO}$ layer on the surface of the powders.

The activation energy ( $E a)$ of $\mathrm{H}_{2}$ desorption may be estimated from the Arrhenius equation:

$k=A \cdot \exp (-E a / R T)$

where $k$ is a temperature dependent reaction rate constant, $A$ is the pre-exponential factor, $R$ is the gas constant and $T$ is the absolute temperature. The $k$ values can be obtained by analyzing the isothermal $\mathrm{H}_{2}$ desorption curves with appropriate kinetic rate expressions, which are derived from the corresponding solid-state reaction mechanism models such as nucleation, geometrical contraction, diffusion and various reaction order models. Therefore, the model parameters obtained from the fitting of desorption data with suitable models also reflects the 
desorption mechanism. So, the desorption curves have been analyzed using the JohnsonMehl-Avrami (JMA) equation [41-43]:

$\alpha(t)=1-\exp \left[-(k t)^{n}\right]$

where $\alpha$ is the phase fraction transformed at time $t$ and $n$ is the Avrami exponent. The JMA fitting of experimental data of hydrogen desorption from $\mathrm{MgH}_{2} / \mathrm{BaRuO}_{3}$ ball milled mixture are shown in Figure $4 \mathrm{~b}$ as continuous lines. The obtained values of $n$ and $k$ are reported in Figure 5 as a function of the inverse temperature, together with the same results obtained for commercial $\mathrm{MgH}_{2}$ and ball milled $\mathrm{MgH}_{2}$. From the linear fit of $\ln (k)$ as a function of $1 / T$, the $E a$ values were obtained according to eq. (4) and turned out equal to $170 \mathrm{kJmol}^{-1}, 140$ and $130 \mathrm{kJmol}^{-1}$ for commercial $\mathrm{MgH}_{2}$, ball milled $\mathrm{MgH}_{2}$ and $\mathrm{MgH}_{2} / \mathrm{BaRuO}_{3}$ ball milled mixture, respectively. Due to the progressive approaching of the equilibrium temperature at the desorption pressure $(0.1 \mathrm{MPa})$ on decreasing temperatures [26], a correction of the kinetic constants obtained at various temperatures with a constant pressure has been suggested [44]. In the case of a constant sample geometry, the kinetic constant, $\mathrm{k}(\mathrm{T}, \mathrm{P})$, obtained from the JMA analysis (eq. 5) can be normalized by the driving force, $\mathrm{g}\left(\mathrm{P} / \mathrm{P}_{\text {eq }}\right)$, so that a purely kinetic constant, $\mathrm{h}(\mathrm{T})$, can be obtained. The driving force depends on the ratio $\mathrm{P} / \mathrm{P}_{\mathrm{eq}}$, where $\mathrm{P}$ is the pressure of the desorption experiment $\left(0.1 \mathrm{MPa}\right.$ in these experiments) and $\mathrm{P}_{\mathrm{eq}}$ is the equilibrium pressure at the temperature of the experiment $[44,45]$. Attempts to apply the correction for the driving force led to a significant decrease of the correlation coefficient for the linear regression in the Arrhenius plot of Figure 5, with the consequence of unreasonable values for the activation energy. So, row values of the kinetic constant have been taken for the calculation of the activation energies, in agreement with similar studies $[10,46]$. The application of the JMA equation to the hydrogen desorption in $\mathrm{MgH}_{2}$ lead to different values for the Avrami coefficient $[43,46]$, that have been associated to various reaction mechanisms. From the results shown in Figure 5, it appears clear that the $n$ values increase for decreasing 
temperature. The temperature dependence of the $n$ value might be related to the change in the driving force for the phase transformation, as discussed above. In all cases, $\mathrm{n}$ values turn out in the range between 1 and 3. In addition, $\mathrm{n}$ values are the highest for commercial $\mathrm{MgH}_{2}$, become lower for the ball milled $\mathrm{MgH}_{2}$ and are the lowest for $\mathrm{MgH}_{2} / \mathrm{BaRuO}_{3}$ ball milled mixtures, suggesting an active role of the ball milling process and of the additive in changing the reaction mechanism for hydrogen desorption.

The results of hydrogen desorption measured by DSC for $\mathrm{MgH}_{2} / \mathrm{BaRuO}_{3}$ ball milled mixture at different heating rates $(5,10,20$ and $40 \mathrm{~K} / \mathrm{min})$ are shown in Figure 6 . An apparent endothermic signal is observed in correspondence of the hydrogen desorption, because of the change in thermal conductivity of the gas surrounding the sample [47]. For pure $\mathrm{MgH}_{2}$, a single DSC signal is usually obtained for hydrogen desorption [43]. On the contrary, for the ball milled $\mathrm{MgH}_{2} / \mathrm{BaRuO}_{3}$ mixture, multiple peaks signal appeared (Figure 6), suggesting the occurrence of hydrogen desorption from different crystallographic sites or phases.

The activation energy for hydrogen desorption has been estimated by Kissinger method according to [48]:

$d\left(\ln \left(\beta / T_{p}^{2}\right) / d\left(T_{p}^{-1}\right)=-E a / R\right.$

where $\beta$ is the heating rate and $T_{p}$ is the peak temperature in the DSC trace. The obtained $E a$ values were $140 \mathrm{kJmol}^{-1}, 120 \mathrm{kJmol}^{-1}$ and $90 \mathrm{kJmol}^{-1}$ for commercial $\mathrm{MgH}_{2}$, ball milled $\mathrm{MgH}_{2}$ and $\mathrm{MgH}_{2} / \mathrm{BaRuO}_{3}$ ball milled mixture, respectively.

The $E a$ values for hydrogen desorption from powdered $\mathrm{MgH}_{2}$ with coarse microstructure reported in the literature range from $300 \mathrm{kJmol}^{-1}$ [44] down to $140 \mathrm{kJmol}^{-1}$ [11]. The ball milling itself accelerates the reaction of hydrogen desorption from $\mathrm{MgH}_{2}$ simply because of a reduced diffusion path, but it generally introduces a significant amount of $\mathrm{MgO}$, forming a diffusion barrier at the surface of the particles. In this case, a value of activation energy around $120 \mathrm{kJmol}^{-1}$ range has been obtained, in good agreement with results previously 
reported in the literature [42]. The presence of the additive promotes the hydrogen insertion inside the oxide layer, further reducing the $E a$ values. In fact, values around $60-70 \mathrm{kJmol}^{-1}$ have been reported when $\mathrm{Nb}_{2} \mathrm{O}_{5}$ is added during ball milling [22,23]. In particular, during the hydrogen sorption cycling of the $\mathrm{MgH}_{2} / \mathrm{Nb}_{2} \mathrm{O}_{5}$ mixture, a ternary $\mathrm{Mg}_{3} \mathrm{Nb}_{6} \mathrm{O}_{11}$ compound is formed at the surface [25], which has been shown to be able to absorb $\mathrm{H}_{2}$ reversibly in the bulk [37].

After $\mathrm{BaRuO}_{3}$ addition, the $E a$ value for hydrogen desorption from $\mathrm{MgH}_{2}$ becomes significantly lower with respect to that obtained for the commercial powder. In both cases, the $E a$ values obtained from isothermal desorption measurements turn out higher than those obtained from scanning measurements, likely because of the different experimental conditions (i.e. $\mathrm{H}_{2}$ pressure, driving force), which might affect the reaction mechanism. On the other hand, the peculiar properties of $\mathrm{BaRuO}_{3}$ as "oxide bronze" seems to be related to its role in promoting hydrogen desorption. In fact, the mixing of $\mathrm{BaRuO}_{3}$ with $\mathrm{MgO}$ at the surface of the particles during ball milling, might produce preferential paths for hydrogen, which turn out in a decreasing of the apparent activation energy. So, it can be concluded that the $\mathrm{BaRuO}_{3}$ addition during ball-milling of $\mathrm{MgH}_{2}$ promotes the formation of an active system with respect to $\mathrm{H}_{2}$ release, as already demonstrated for other oxide systems.

\section{Conclusions}

In this paper it has been demonstrated that the $\mathrm{BaRuO}_{3}$ absorbs hydrogen at $\mathrm{RT}$ and $6.4 \mathrm{MPa}$ $\mathrm{H}_{2}$ pressure, leading to rhombohedral distorted phase, with a c-axis elongated with respect to the parent structure. During TPD, the hydrogenated oxide phase releases mainly hydrogen, coupled with a small amount of water, suggesting the occurrence of an oxide-bronze behaviour. The rate of the $\mathrm{H}_{2}$ desorption in $\mathrm{MgH}_{2}$ is accelerated by ball milling with addition of $\mathrm{BaRuO}_{3}$. In particular, the ball milled $\mathrm{MgH}_{2} / \mathrm{BaRuO}_{3}$ mixture showed a value of the 
apparent activation energy for hydrogen desorption significantly lower with respect to that obtained for commercial $\mathrm{MgH}_{2}$, likely due to a change in the reaction mechanism. The peculiar properties of $\mathrm{BaRuO}_{3}$ as a promoter for hydrogen desorption from $\mathrm{MgH}_{2}$ have been correlated with its aptitude to absorb hydrogen in the bulk structure.

\section{References}

[1] B. Sakintuna, B. Weinberger, F. Lamari-Darkrim, M. Hirscher, B. Dogan, Int. J. Hydrogen Energy 32 (2007) 1121.

[2] L. Zaluski, A. Zaluska, J. O. Ström-Olsen, J. Alloys Compd. 253 (1997) 70.

[3] H. Imamura, K. Masanari, M. Kusuhara, H. Katsumoto, T. Sumi, Y. Sakata, J. Alloys Compd. 386 (2005) 211.

[4] M. Zhu, H. Wang, L. Z. Ouyang, M. Q. Zeng, Int. J. Hydrogen Energy 31 (2006) 251.

[5] A. Zaluska, L. Zaluski, J. O. Ström-Olsen, Appl Phys A. 72 (2001) 157.

[6] R. Wiswall, in: G. Alefeld and J. Völkl, Editors, Topics in Applied Physics, Vol.29, Hydrogen in Metals 2, Springer, Berlin/Heidelberg (1978), p. 209.

[7] Y. Fukai, The metal-hydrogen, system. Basic bulk properties, Springer Series in Material Science Vol. 21, Springer-Verlag, Berlin (1993).

[8] L. Schlapbach, A.Zuttel, Nature, 414 (2001) 353.

[9] K. F. Aguey-Zinsou, J. R. A. Fernandez, T. Klassen, R. Bormann, Int. J. Hydrogen Energy 32 (2007) 2400.

[10] J. Huot, M. L. Tremblay, R. Schulz, J Alloys Compd. 356 (2003) 603.

[11] D. Fatay, A. Revesz, T. Spassov, J. Alloys Compd. 399 (2005) 237.

[12] J. L. Bobet, E. Akiba, Y. Nakamura, B. Darriet, Int. J. Hydrogen Energy 25 (2000) 987.

[13] C. X. Shang, M. Bououdina, Z. X. Guo, J. Alloys Compd. 349 (2003) 217. 
[14] J. Huot, J. F. Pelletier, L. B. Lurio, M. Sutton, R. Schulz, J. Alloys Compd. 348 (2003) 319.

[15] M. Q. Fan, L. X. Sun, Y. Zhang, F. Xu, J. Zhang, H. L. Chu. Int. J. Hydrogen Energy $33(2008) 74$.

[16] A. Patah, A. Takasaki, J. S. Szmyd, Int. J. Hydrogen Energy 34 (2009) 3032.

[17] F. Dolci, M. Baricco, P. P. Edwards, E. Giamello, Int. J. Hydrogen Energ. 33 (2008) 3085 .

[18] C. Zhi, T. Chao, P. Hui, Y. Huabin, Int. J. Hydrogen Energy 35 (2010) 8289.

[19] W. Oelerich, T. Klassen, R. Bormann, J. Alloys Compd. 315 (2001) 237.

[20] K. S. Jung, E. Y. Lee, K. S. Lee, J. Alloys Compd. 421 (2006) 179.

[21] G. Barkhordarian, T. Klassen, R. Bormann, Scripta Mater. 49 (2003) 213.

[22] G. Barkhordarian, T. Klassen, R. Bormann, J. Alloys Compd. 364 (2004) 242.

[23] N. Hanada, T. Ichikawa, S. Hino, H. Fujii, J. Alloys Compd. 420 (2006) 46.

[24] G. Barkhordarian, T. Klassen, R. Bormann, J. Phys. Chem. B 110 (2006) 11020.

[25] O. Friedrichs, J. C. Sanchez-Lopez, C. Lopez-Cartes, T. Klassen, R. Bormann, A. Fernandez, J. Phys. Chem. 110 (2006) 7845.

[26] M. W. Rahman, A. Castellero, S. Enzo, S. Livraghi, E. Giamello, M. Baricco J. Alloys Compd. 509S (2011) S438.

[27] K. Schlberg, S. T. Pantelides, S. J. Pennycook, J. Am. Chem. Soc. 123 (2001) 6609.

[28] S. Nieto, R. Polanco, R. Roque-Malherbe, J. Phys. Chem. C 111 (2007) 2809.

[29] Q. Wan, C. L. Lin, X. B. Yu, T. H. Wang, Appl. Phys. Lett. 84 (2004) 124.

[30] S. H. Lim, J. Luo, Z. Zhong, W. Ji, J. Lin, Inorg. Chem. 44 (2005) 4124.

[31] F. Dolci, M. Di Chio, M. Baricco, E. Giamello, J. Mater. Sci. 42 (2007) 7180.

[32] F. Dolci, M. Di Chio, M. Baricco, E. Giamello, Mater. Res. Bull. 44 (2009) 194.

[33] C. Chabanier, D. Guay J. Electroanal. Chem. 570 (2004) 13. 
[34] M. Shelef, R. A. D.Betta, K. Otto, J. Inorg. Nucl. Chem. 38 (1976) 99.

[35] P. C. Donohue, L. Katz, R. Ward, Inorg Chem. 4 (1965) 306.

[36] L. Lutterotti, S. Matthies, H-R. Wenk, A. J. Schulz, J. Richardon, J. Appl. Phys. 81 (1997) 594. MAUD is available at http://www.ing.unitn.it/ maud.

[37] M. W. Rahman, S. Livraghi, F. Dolci, M. Baricco, E. Giamello, Int. J. Hydrogen Energy 36 ( 2011) 7932.

[38] A. Santoro, I. N. Sora, Q. Huang, J. Solid State Chem. 151 (2000) 245.

[39] B. Reichman, A. J. Bard. J. Electrochem Soc. 127 (1980) 241.

[40] M. A. B. Gomes, L. O. D. Bulhoes, S. C. De Castro, A. J. Damiao, J. Electrochem. Soc. 137 (1990) 3067.

[41] M. Avrami, J. Chem. Phys. 7 (1939) 1103.

[42] J. Huot, G. Liang, S. Boily, A. Van Neste, R. Schulz, J. Alloys Compd. 293-295 (1999) 495.

[43] J. F. Fernandez, C. R. Sanchez, J. Alloys Compd. 356-357 (2003) 348.

[44] J. F. Fernandez, C. R. Sanchez, J. Alloys Compd. 340 (2002) 189.

[45] L. Pasquini, E. Callini, E. Piscopiello, A. Montone, M. Vittori Antisari, E. Bonetti, Appl. Phys. Lett. 94 (2009) 041918.

[46] T. R. Jensen, A. Andreasen, T. Vegge, J. W. Andreasen, K. Stahl, A. S. Pedersen, M. M. Nielsen, A. M. Molenbroek, F. Besenbacher, Int. J. Hydrogen Energy 31 (2006) 2052.

[47] M. Di Chio, S. Livraghi, M. Baricco J. Alloys Compd. 426 (2006) 180.

[48] H. E. Kissinger, Anal. Chem. 29 (1957) 1702.

\section{Figure captions}


Figure 1. The XRD pattern of: $\mathrm{BaRuO}_{3}$ powders as prepared from solid state synthesis of $\mathrm{BaO}+\mathrm{Ru}$ (pattern a); $\mathrm{BaRuO}_{3}$ powders after reactive milling under $0.5 \mathrm{MPa}$ of hydrogen (pattern b); $\mathrm{BaRuO}_{3}$ powders subjected to a hydrogenation at $6.5 \mathrm{MPa}$ (pattern c) and $\mathrm{BaRuO}_{3}$ powders obtained after TPD of hydrogenated sample (pattern d). Experimental data points are dots, full lines are the result of the Rietveld fit to the data. The hkl sequence of peaks for rhombohedral $\mathrm{BaRuO}_{3}$ has been reported at the bottom of the figure.

Figure 2. TPD-MS profiles as a function of temperature for $\mathrm{BaRuO}_{3}$ powders as-prepared (dashed lines) and after hydrogen loading at $6.5 \mathrm{MPa}$ (continuous lines). $\mathrm{H}_{2}$ and $\mathrm{H}_{2} \mathrm{O}$ desorption are reported in top and bottom figure, respectively. Note the different scale values of the graphs.

Figure 3. XRD patterns of the mixtures of $1 \mathrm{~mol} \%$ of $\mathrm{BaRuO}_{3}$ and commercial $\mathrm{MgH}_{2}$ powders as mixed (bottom curve) and subjected to a ball milling treatment of $12 \mathrm{~h}$ (top pattern). Experimental data points are dots, full lines are the result of the Rietveld fit to the data. The as-mixed mixture displays weak presence of hexagonal magnesium phase. In the ball milled specimen it was assessed the weak presence of periclase $\mathrm{MgO}$ and of a $\gamma-\mathrm{MgH} 2$ orthorhombic phase.

Figure 4. Hydrogen desorption measured with a Sievert-type equipment as a function of time at hydrogen pressure of $0.1 \mathrm{MPa}$. Top, figure a: comparison among desorption at $593 \mathrm{~K}$ from as-received $\mathrm{MgH}_{2}$ (squares), ball milled $\mathrm{MgH}_{2}$ (circles) and $\mathrm{MgH}_{2} / \mathrm{BaRuO}_{3}$ ball milled mixture (triangles). Dashed lines are a guide for the eyes. Bottom, figure b: desorption from $\mathrm{MgH}_{2} / \mathrm{BaRuO}_{3}$ ball milled mixture at various temperatures, as indicated in the figure. Points: experimental data. Lines: fitting curves on the basis of eq. (5). 
Figure 5. Rate constant, k (full points), and Avrami coefficient, n (open points), as a function of the inverse temperature for commercial $\mathrm{MgH}_{2}$ (squares), ball milled $\mathrm{MgH}_{2}$ (circles) and $\mathrm{MgH}_{2} / \mathrm{BaRuO}_{3}$ ball milled mixture (triangles).

Figure 6. DSC traces as a function of temperature for hydrogen desorption from $\mathrm{MgH}_{2} / \mathrm{BaRuO}_{3}$ ball milled mixture at various heating rates, as reported in the graphs.

Figure 7. Kissinger plot for commercial $\mathrm{MgH}_{2}$ (squares), ball milled $\mathrm{MgH}_{2}$ (circles) and $\mathrm{MgH}_{2} / \mathrm{BaRuO}_{3}$ ball milled mixture (triangles) based on the results of DSC measurements. 
Interaction of $\mathrm{BaRuO}_{3}$ with hydrogen studied.

$\mathrm{BaRuO}_{3}$ is able to release hydrogen after absorption.

A distorted rhomohedral phase is formed in $\mathrm{BaRuO}_{3}$ after hydrogen absorption.

A mixture of $\mathrm{BaRuO}_{3}$ with $\mathrm{MgH}_{2}$ is able to desorb hydrogen much faster than the parent materials. The interaction of hydrogen with the oxide additive is a crucial aspect for improving the hydrogen desorption rate. 


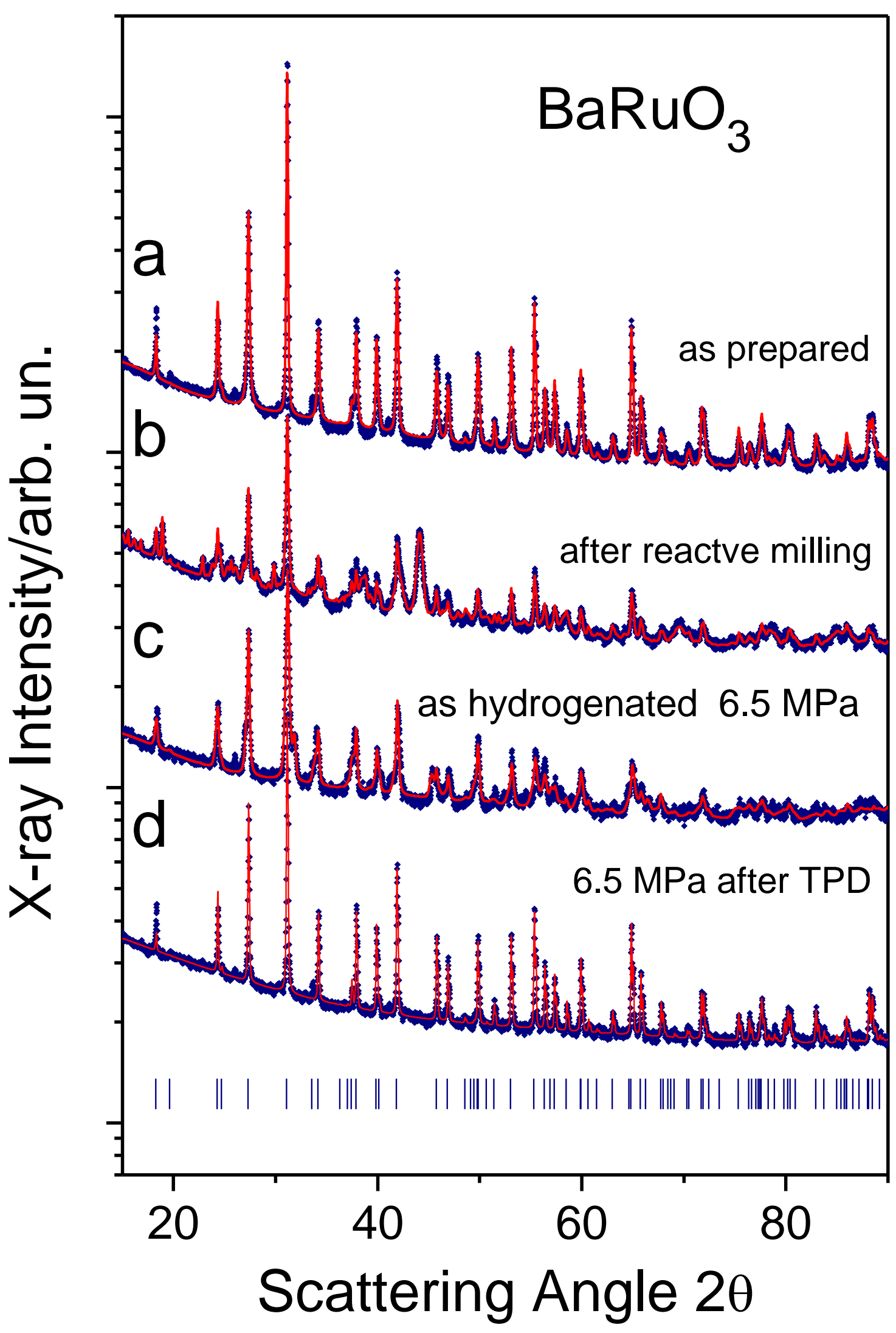


Baricco et al. Figure 2

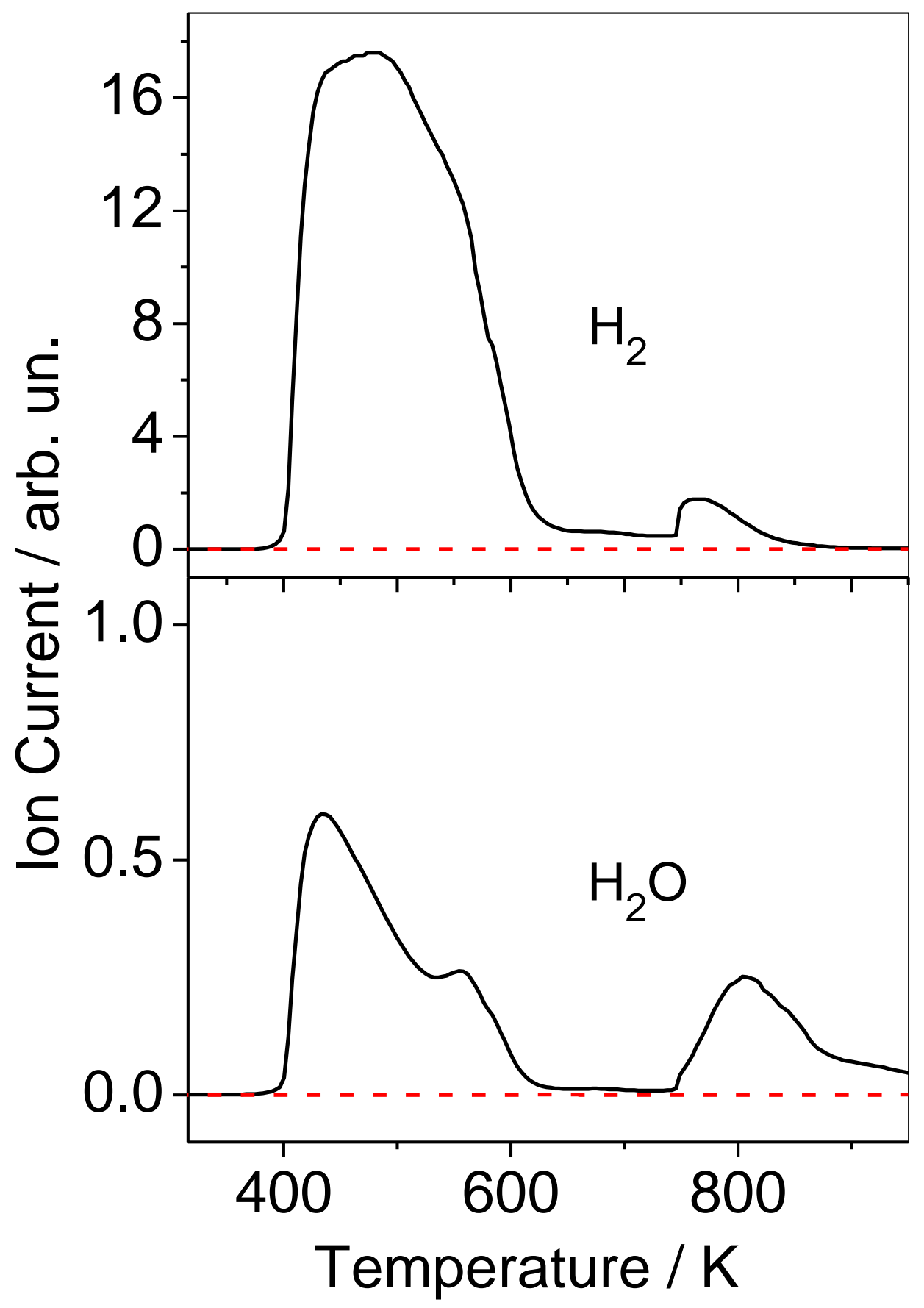


Baricco et al. Figure 3

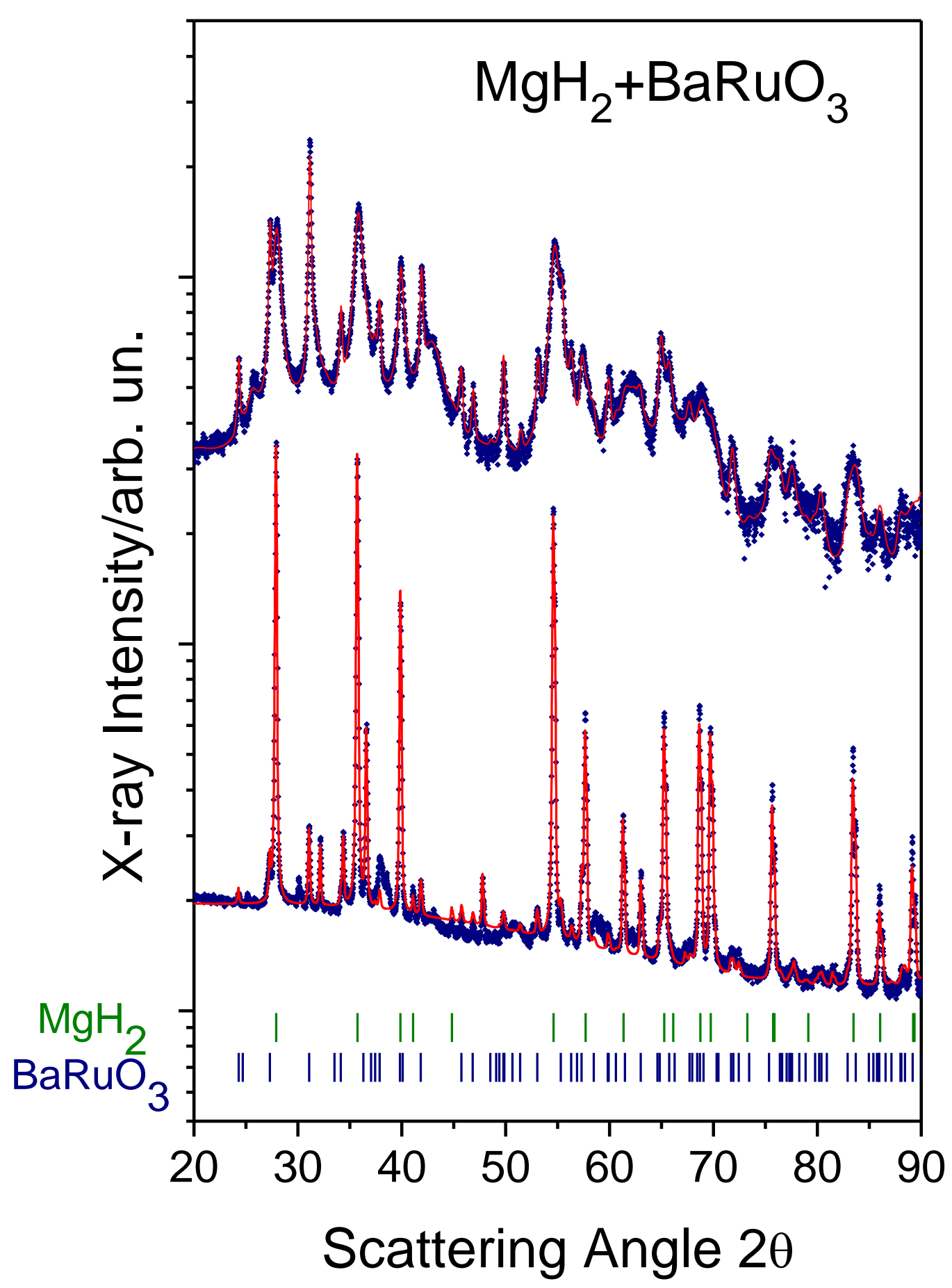


Baricco et al. Figure 4

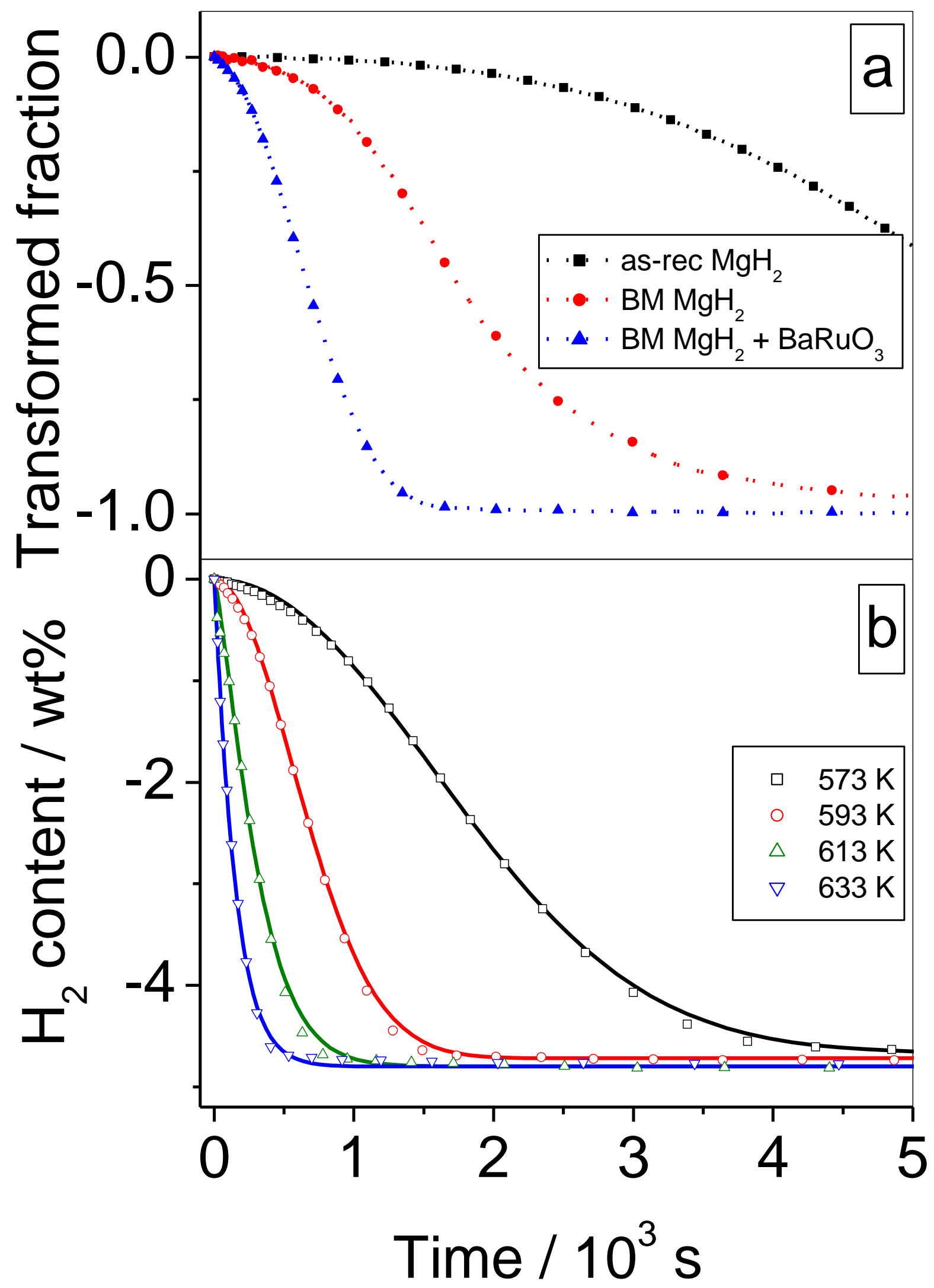


Baricco et al. Figure 5

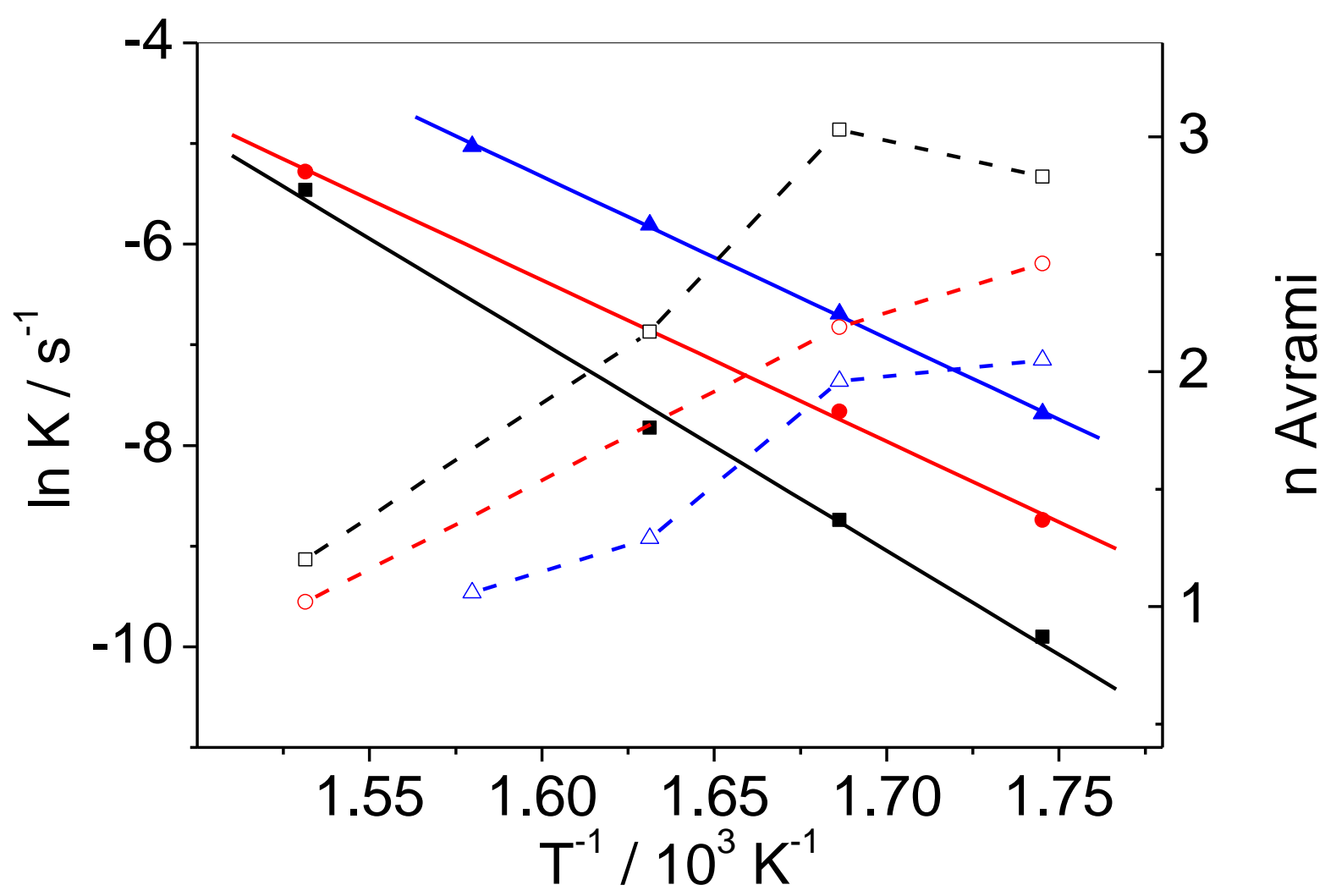


Baricco et al. Figure 6

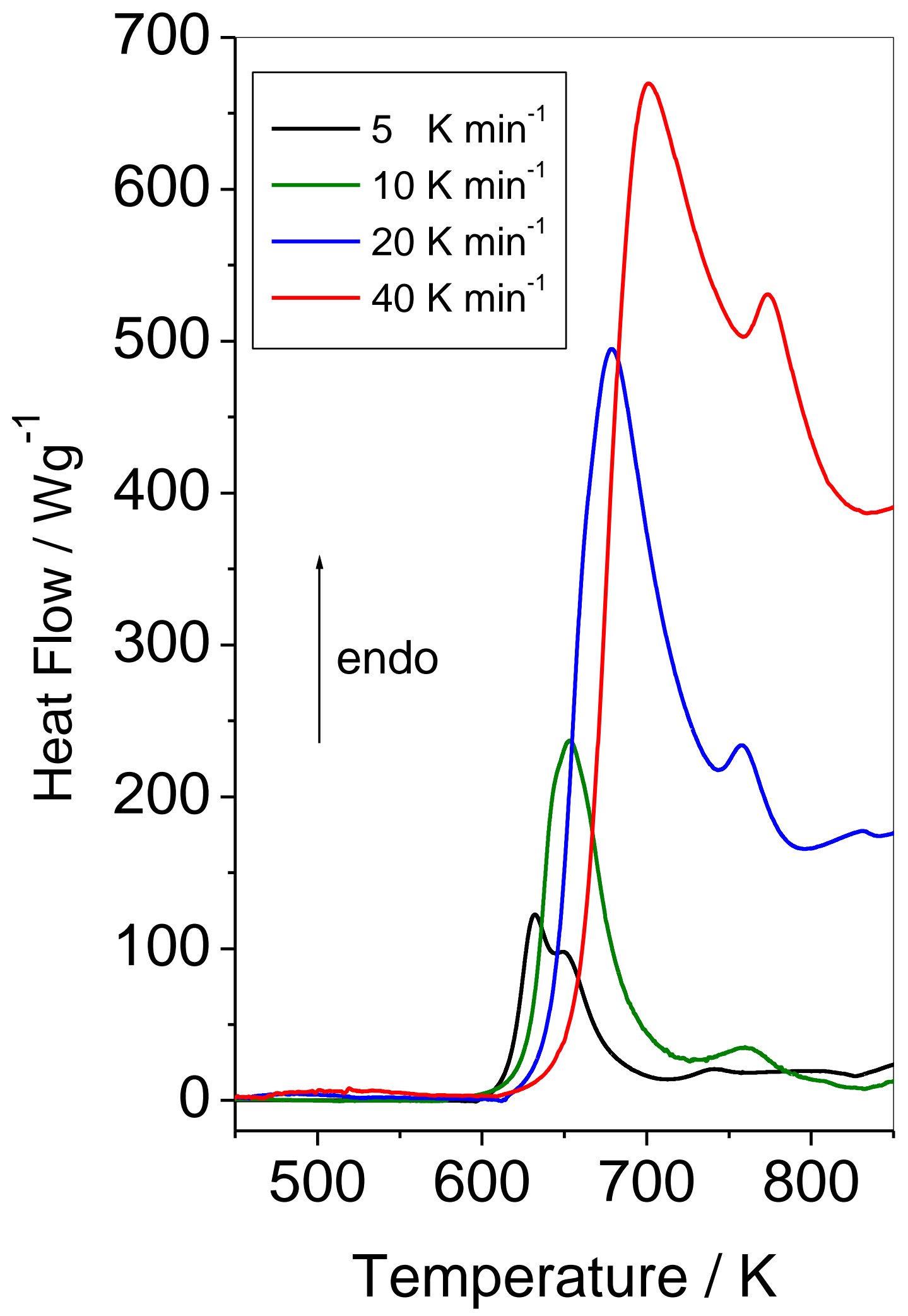


Baricco et al. Figure 7

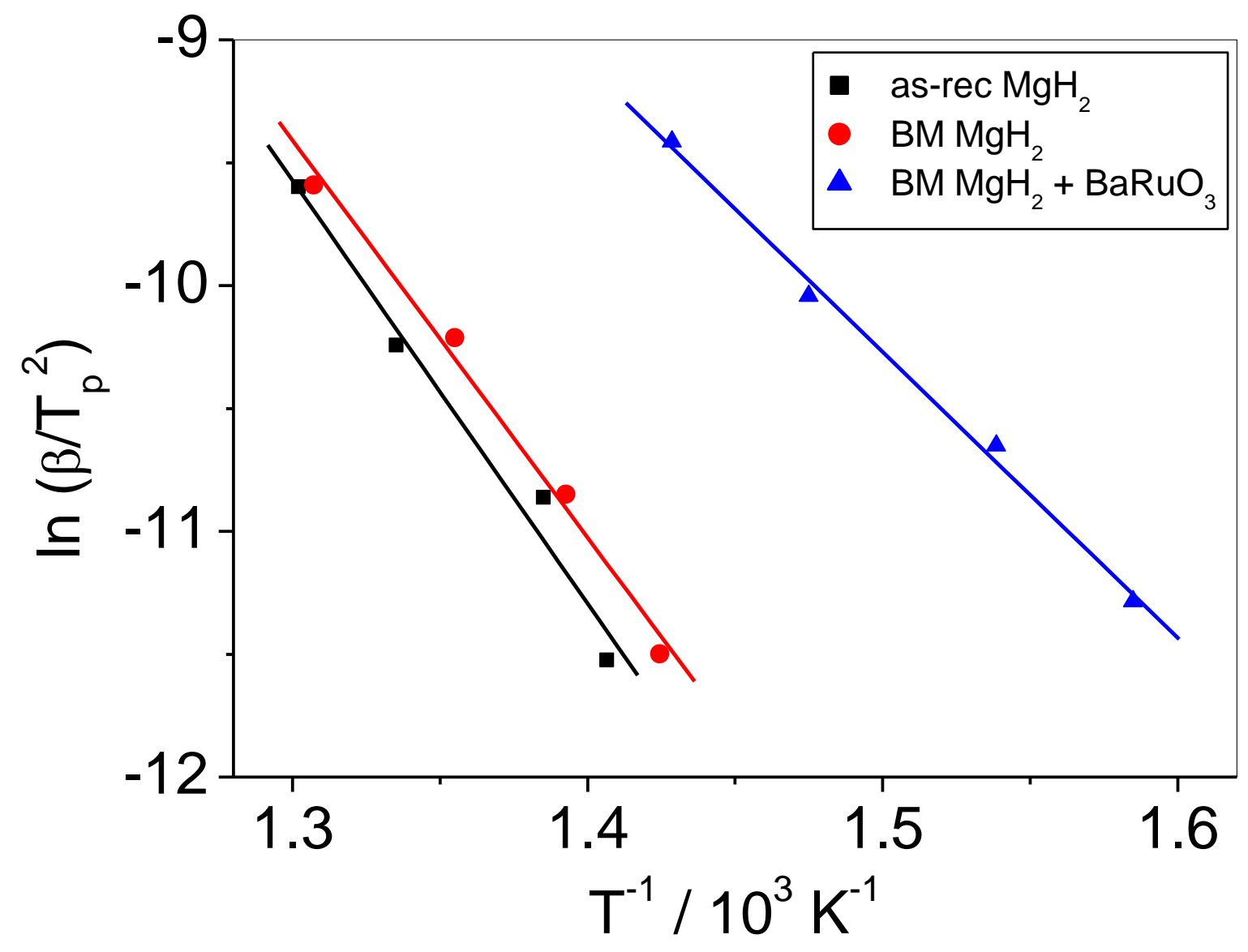

